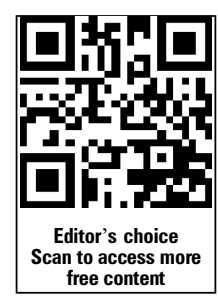

${ }^{1}$ Department of Cardiology, Assistance Publique-Hôpitaux de Paris, Bichat Hospital, Paris, France

${ }^{2}$ INSERM U698, Bichat Hospital, Paris, France ${ }^{3}$ University Paris 7, Paris, France

${ }^{4}$ Department of Epidemiology, Biostatistic and Clinical research, Assistance Publique - Hôpitaux de Paris, Bichat Hospital, Paris, France ${ }^{5}$ Centre de Ressources Biologique, Assistance Publique-Hôpitaux de Paris, Bichat Hospital, Paris, France ${ }^{6}$ Centre d'Investigation Clinique 007, Assistance PubliqueHôpitaux de Paris, Bichat Hospital, Paris, France ${ }^{7}$ Department of Medicine, Québec Heart and Lung Institute, Laval University, Québec city, Québec, Canada ${ }^{8}$ Division of Cardiovascular Disease, Mayo Clinic, Rochester, Minnesota, USA

\section{Correspondence to} Dr David Messika-Zeitoun, AP-HP, Cardiovascular division, Bichat Hospital, 46 rue Henri Huchard, Paris 75018, France; david.messika-zeitoun@bch. aphp.fr

Received 11 November 2014 Revised 15 December 2014 Accepted 15 January 2015 Published Online First 5 February 2015

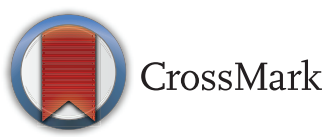

To cite: Nguyen $\mathrm{V}$, Cimadevilla C, Estellat C, et al. Heart 2015;101: 943-947.

\title{
Haemodynamic and anatomic progression of aortic stenosis
}

\author{
Virginia Nguyen, ${ }^{1,2,3}$ Claire Cimadevilla, ${ }^{1,2}$ Candice Estellat, ${ }^{4}$ Isabelle Codogno, ${ }^{1}$ \\ Virginie Huart, ${ }^{5}$ Joelle Benessiano, ${ }^{5}$ Xavier Duval, ${ }^{6}$ Philippe Pibarot ${ }^{7}$ \\ Marie Annick Clavel, ${ }^{8}$ Maurice Enriquez-Sarano, ${ }^{8}$ Alec Vahanian, ${ }^{1,2,3}$ \\ David Messika-Zeitoun ${ }^{1,2,3}$
}

\begin{abstract}
Background Aortic valve stenosis (AS) is a progressive disease, but the impact of baseline AS haemodynamic or anatomic severity on AS progression remains unclear. Methods In 149 patients (104 mild AS, 36 moderate AS and 9 severe AS) enrolled in 2 ongoing prospective cohorts (COFRASA/GENERAC), we evaluated AS haemodynamic severity at baseline and yearly, thereafter, using echocardiography (mean pressure gradient (MPG)) and AS anatomic severity using CT (degree of aortic valve calcification (AVC)).

Results After a mean follow-up of $2.9 \pm 1.0$ years, mean MGP increased from $22 \pm 11$ to $30 \pm 16 \mathrm{~mm} \mathrm{Hg}$ $(+3 \pm 3 \mathrm{~mm} \mathrm{Hg} /$ year), and mean AVC from $1108 \pm 891$ to $1640 \pm 1251$ AU (arbitrary units) (+188 \pm 176 AU/year). Progression of AS was strongly related to baseline haemodynamic severity $(+2 \pm 3 \mathrm{~mm} \mathrm{Hg} /$ year in mild $A S$, $+4 \pm 3 \mathrm{~mm} \mathrm{Hg} /$ year in moderate AS and $+5 \pm 5 \mathrm{~mm} \mathrm{Hg} /$

(AVC) is the main process leading to AS, and can be accurately and quantitatively measured (calcium score) in vivo using multislice CT (MSCT). ${ }^{6}$ The degree of AVC-AS anatomic severity-is closely related to AS haemodynamic severity as assessed using echocardiography and can be considered as a complementary method for the evaluation of severity of AS in difficult clinical situations. $^{78}$

Calcific AS is a progressive disease, ${ }^{9}$ and despite recent progress, determinants of AS progression remain unclear. AS progression is highly variable among individuals, and the impact of baselinehaemodynamic or anatomic-AS severity remains unknown. Thus, in 2 ongoing prospective cohorts, we aimed to evaluate the impact of baseline AS severity assessed, either by using echocardiography (haemodynamic assessment) or MSCT (anatomic assessment) on AS progression.
\end{abstract} year in severe AS $(p=0.01))$, and baseline

haemodynamic severity was an independent predictor of haemodynamic progression $(p=0.0003)$. Annualised haemodynamic and anatomic progression rates were significantly correlated $(r=0.55, p<0.0001)$, but AVC progression rate was also significantly associated with baseline haemodynamic severity $(+141 \pm 133 \mathrm{AU} /$ year in mild AS, $+279 \pm 189$ AU/year in moderate AS and +361 $\pm 293 \mathrm{AU} /$ year in severe $\mathrm{AS}, \mathrm{p}<0.0001$ ), and both baseline MPG and baseline AVC were independent determinants of AVC progression ( $p<0.0001)$.

Conclusions AS progressed faster with increasing haemodynamic or anatomic severity. Our results suggest that a medical strategy aimed at preventing AVC progression may be useful in all subsets of patients with AS including those with severe AS and support the recommended closer follow-up of patients with AS as AS severity increases.

Clinical trial registration COFRASA (clinicalTrial.gov number NCT 00338676) and GENERAC (clinicalTrial.gov number NCT00647088).

\section{INTRODUCTION}

Aortic valve stenosis (AS) is the most common valvular heart disease in Western countries. ${ }^{1}$ AS affects $2 \%-7 \%$ of people aged over 70 years $^{23}$ and its prevalence is going to dramatically increase with the ageing of the population. AS haemodynamic severity is usually assessed using echocardiography based on mean gradient, peak velocity (PV) and calculation of the aortic valve area (AVA). ${ }^{4}$ Aortic valve calcification

\section{METHODS}

\section{Study design}

Patients with degenerative AS, enrolled between November 2006 and May 2013 in two ongoing prospective studies, COFRASA (clinicalTrial.gov number NCT 00338676) and GENERAC (clinicalTrial.gov number NCT00647088), with at least 2 years of follow-up were considered in the present study. determinants of AS occurrence and progression, and all participants underwent a comprehensive clinical, transthoracic echocardiography (TTE) and MSCT evaluation at study entry and yearly thereafter. Inclusion criteria are pure, at least mild (defined by a mean pressure gradient (MPG) $\geq 10 \mathrm{~mm} \mathrm{Hg}$ and aortic valve structural changes (thickening/calcification)) asymptomatic AS. Exclusion criteria were AS due to rheumatic disease or radiotherapy, previous infective endocarditis, more than mild coexisting aortic regurgitation (defined by a vena contracta width $\geq 3 \mathrm{~mm}$ or a regurgitant volume $\geq 30 \mathrm{~mL}$ ) or associated valvular disease and severe renal insufficiency (creatinine clearance $\leq 30 \mathrm{~mL} / \mathrm{min}$ ). Echocardiographic and MSCT measurements were performed with each blinded from the other. The study was approved by our regional ethics committee, and all patients gave written informed consent.

\section{Echocardiography}

A comprehensive Doppler echocardiogram was performed at baseline and then on a yearly basis. COFRASA and GENERAC aim at evaluating the 
Severity of AS was evaluated based on PV, MPG and the AVA calculated using the continuity equation ${ }^{10}{ }^{11}$ as recommended by current guidelines. ${ }^{4} 12$ The AVA was calculated as an absolute value and indexed (AVAi) to body surface area (BSA). Mild AS was defined by an MPG $<25 \mathrm{~mm} \mathrm{Hg}$, moderate AS was defined by an MPG between 25 and $40 \mathrm{~mm} \mathrm{Hg}$ and severe AS by an MPG $>40 \mathrm{~mm} \mathrm{Hg}$. Short-axis view in systole was used to differentiate bicuspid from trileaflet aortic valve.

\section{MSCT measurements}

MSCT was performed on the same day as TTE at baseline and also yearly thereafter using a Philips scanner (MX 8000 IDT 16, Phillips Medical Systems, Andover, Massachusetts, USA) or a General Electric scanner (Light speed VCTTM, General Electric Company, Fairfield, Connecticut, USA). A scan run consisted of a prospective acquisition of forty $3 \mathrm{~mm}$ thick contiguous transverse slices. MSCT was performed with a tube current of $75 \mathrm{~A}$ and a voltage of $120 \mathrm{kV}$. Acquisition time was $0.5 \mathrm{~s} /$ slice ECG triggered at $75 \%$ of the RR interval. No contrast enhancement was needed nor was a $\beta$-blocker administered for the purpose of the examination. Measurements were performed using dedicated semiautomatic software (Heart Beat Calcium Scoring, Philips Medical Systems or SmartScore, General Electric Medical Systems). Calcification was defined as four adjacent pixels with density greater than 130 Hounsfield units. The degree of AVC was quantitatively assessed according to the Agatston method (calcium score) and expressed in arbitrary units (AU). AVC was defined as calcification within the valve leaflets including the aortic annulus and the aortic wall immediately adjacent to the leaflets. ${ }^{7}$ Two MSCT runs were performed sequentially with a $1 \mathrm{~mm}$ or $2 \mathrm{~mm}$ initial interval. Each run was independently scored and the two scores were averaged. Radiation exposure was typically between $2 \mathrm{mSV}$ and $3 \mathrm{mSV}$. The accuracy and reproducibility of MSCT assessment of the degree of calcification has been previously validated. ${ }^{5-7}$ Intraobserver variability was $4 \pm 10 \%(68 \pm 130 \mathrm{AU})$ and interobserver variability was $6 \pm 7 \%(74 \pm 77 \mathrm{AU})$. Scans with motion artefacts precluding AVC measurements were excluded.

\section{Statistical analysis}

Continuous variables were expressed as mean $\pm \mathrm{SD}$, median ( 25 th and 75 th percentile), or number of patients (per cent). Correlations between calcium score and AS haemodynamic severity were tested with linear and non-linear regressions, and the model using the square root of AVC was retained as providing the best fit. Annualised progression was calculated as ((final measurement-baseline measurement)/follow-up duration) for haemodynamic (MPG) and anatomic (AVC score) measurements. Comparisons between terciles of AVC progression were performed using Kruskal-Wallis test, Mann-Whitney-Wilcoxon test, $\chi^{2}$ test or Fisher exact test, as appropriate. Linear regressions in univariate analysis and in multivariate analysis after adjustment for age, gender and aortic valve anatomy (bicuspid or trileaflet aortic valve) were used to determine the association between anatomic or haemodynamic progression (as a continuous variable) and baseline haemodynamic severity or baseline AVC score. A p value $<0.05$ was considered statistically significant.

\section{RESULTS}

\section{Characteristics of the population}

One hundred and forty-nine patients with at least mild AS and at least 2 years of follow-up were prospectively enrolled. Baseline characteristics of the population are summarised in table 1 (left part). Briefly, mean age was $74 \pm 9$ years, $75 \%$ were male and $93 \%$ in sinus rhythm. The aortic valve was trileaflet in 125 patients (84\%) and bicuspid in 24 (16\%). MGP was 22 $\pm 11 \mathrm{~mm} \mathrm{Hg}$, but there was a wide range of AS severity (median $20 \mathrm{~mm} \mathrm{Hg}$, (10-55)) and 104 patients had mild AS (MPG $<25 \mathrm{~mm} \mathrm{Hg}$ ), 36 patients moderate AS (MPG between 25 to $40 \mathrm{~mm} \mathrm{Hg}$ ) and 9 patients severe AS (MPG >40 mm Hg). Mean AVC score was 1108 \pm 891 AU (median 873, (81-3923)). As previously reported, there was a good correlation between the degree of AVC assessed using MSCT and haemodynamic parameters of AS severity assessed either using the MPG $(\mathrm{r}=0.67, \mathrm{p}<0.0001$; figure 1$)$, the PV $(\mathrm{r}=0.68 ; \mathrm{p}<0.0001)$ or the AVAi $(r=0.47 ; \mathrm{p}<0.0001)$.

\section{Haemodynamic progression}

Mean follow-up was $2.9 \pm 1.0$ years. At the end of follow-up, mean MGP increased to $30 \pm 16 \mathrm{~mm} \mathrm{Hg}$ (median 25, (10-75)) and the yearly mean MPG increase was $3 \pm 3 \mathrm{~mm} \mathrm{Hg} /$ year (median 2, (0-13)). Twelve patients progressed from mild AS to severe AS and 27 patients from moderate AS to severe AS. However, AS progression rate was not uniform and was strongly related to baseline haemodynamic severity (MPG, PV or AVAi at baseline, all $\mathrm{r}>0.29 ; \mathrm{p}<0.0001)$. Thus, AS progression rate was $2 \pm 3 \mathrm{~mm} \mathrm{Hg} /$ year (median 2, (0-13)) in patients with mild AS, $4 \pm 3 \mathrm{~mm} \mathrm{Hg} /$ year (median 3, (0-15)) in patients with moderate AS and $5 \pm 5 \mathrm{~mm} \mathrm{Hg} /$ year (median $4,(0-14)$ ) in patients with severe AS $(p=0.01)$ (figure $2 \mathrm{~A})$. By contrast, progression was not different between patients with trileaflet and bicuspid aortic valve $(3 \pm 3 \mathrm{~mm} \mathrm{Hg} /$ year (median $2,(0-13))$ vs $3 \pm 4 \mathrm{~mm} \mathrm{Hg} /$ year (median 2, $(0-13)), \mathrm{p}=0.70)$ or between male and female patients $(3 \pm 3 \mathrm{~mm} \mathrm{Hg} /$ year (median 2, (0-13)) vs $4 \pm 4 \mathrm{~mm} \mathrm{Hg}$ / year (median 3, $(0-15)), p=0.40)$. After adjustment for age, gender and aortic valve anatomy (bileaflet or trileaflet aortic valve), baseline haemodynamic severity was an independent predictor of haemodynamic progression $(p=0.0003)$. The same results were obtained when PV or AVAi were used instead of MPG.

\section{Anatomic progression}

Final mean AVC score was 1640 1251 AU (median 1341, (196-5246)), and mean AVC increase was $188 \pm 176 \mathrm{AU} /$ year (median 141, (0-787)). There was no difference in AVC progression between patients with trileaflet and bicuspid aortic

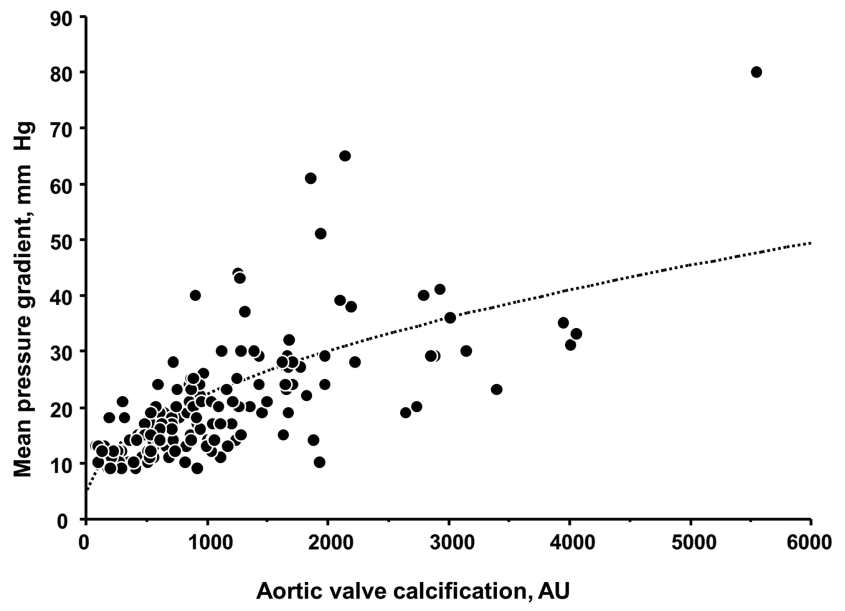

Figure 1 Correlation between the degree of aortic valve calcification expressed in arbitrary units (AU) (x axis) and mean pressure gradient ( $\mathrm{mm} \mathrm{Hg}$ ). 


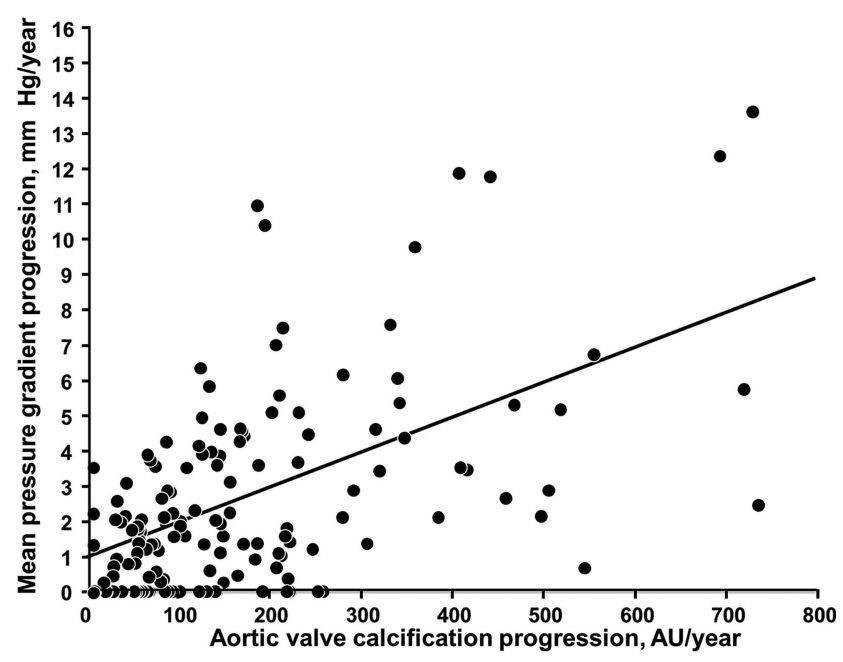

Figure 2 Relationship between changes in degree of aortic valve calcification (expressed in arbitrary unit/year; arbitrary unit (AU)/year) ( $x$ axis) and changes in haemodynamic severity (mean pressure gradient/year, mm Hg/year).

valve $(179 \pm 167 \mathrm{AU} /$ year (median 135, (0-752)) vs 240 $\pm 212 \mathrm{AU} /$ year (median 201, $(0-809)$ ), $\mathrm{p}=0.30$ ) or between male and female patients (196 $\pm 166 \mathrm{AU} /$ year (median 152, $(0-650)$ ) vs $163 \pm 201 \mathrm{AU} /$ year (median 107, $(0-820)$ ), $\mathrm{p}=0.06)$. AVC progression rate was also significantly associated with baseline haemodynamic severity, and AVC progression was 141 $\pm 133 \mathrm{AU} /$ year (median 100, (0-582)) in patients with mild AS, $279 \pm 189$ AU/year (median 241, (0-827)) in patients with moderate AS and $361 \pm 293$ AU/year (median 230, (70-809)) in patients with severe AS $(\mathrm{p}<0.0001)$ (figure $2 \mathrm{~B})$. There was a correct linear correlation between anatomic and haemodynamic changes $(\mathrm{r}=0.55 ; \mathrm{p}<0.0001$; figure 3$)$. However, as for haemodynamic progression, AVC progression was strongly related to baseline AVC load ( $r=0.57 ; \mathrm{p}<0.0001$; figure 4).

We then divided our population into terciles of AVC progression (<85 AU/year, 85-205 AU/year and >205 AU/year). Characteristics of the 149 patients according to AVC terciles of progression are presented in table 1 (right part). Baseline haemodynamic severity (MPG, PV and AVAi) and AVC score

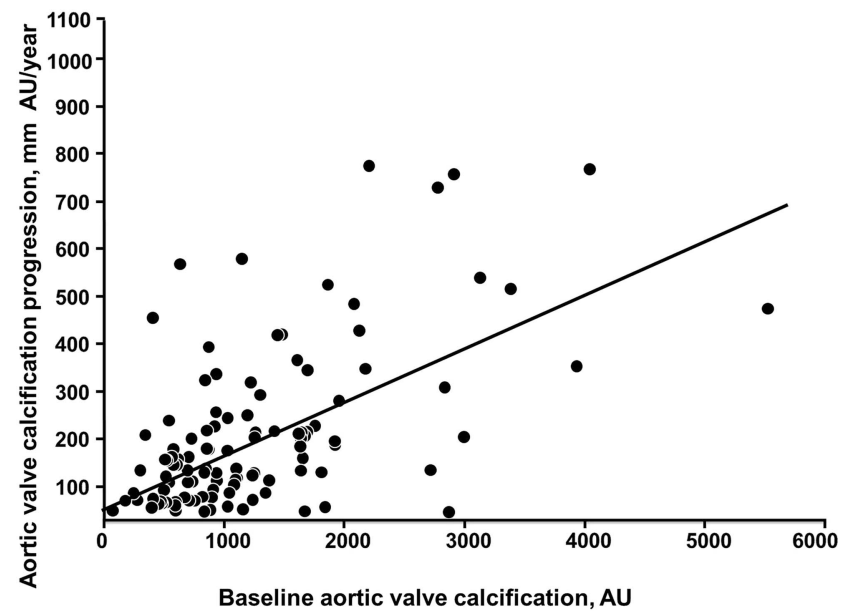

Figure 3 Relationship between the degree of aortic valve calcification at baseline (expressed in arbitrary unit (AU)) (x axis) and the increase in the degree of aortic valve calcification (arbitrary unit/year, AU/year). AS, aortic valve stenosis.
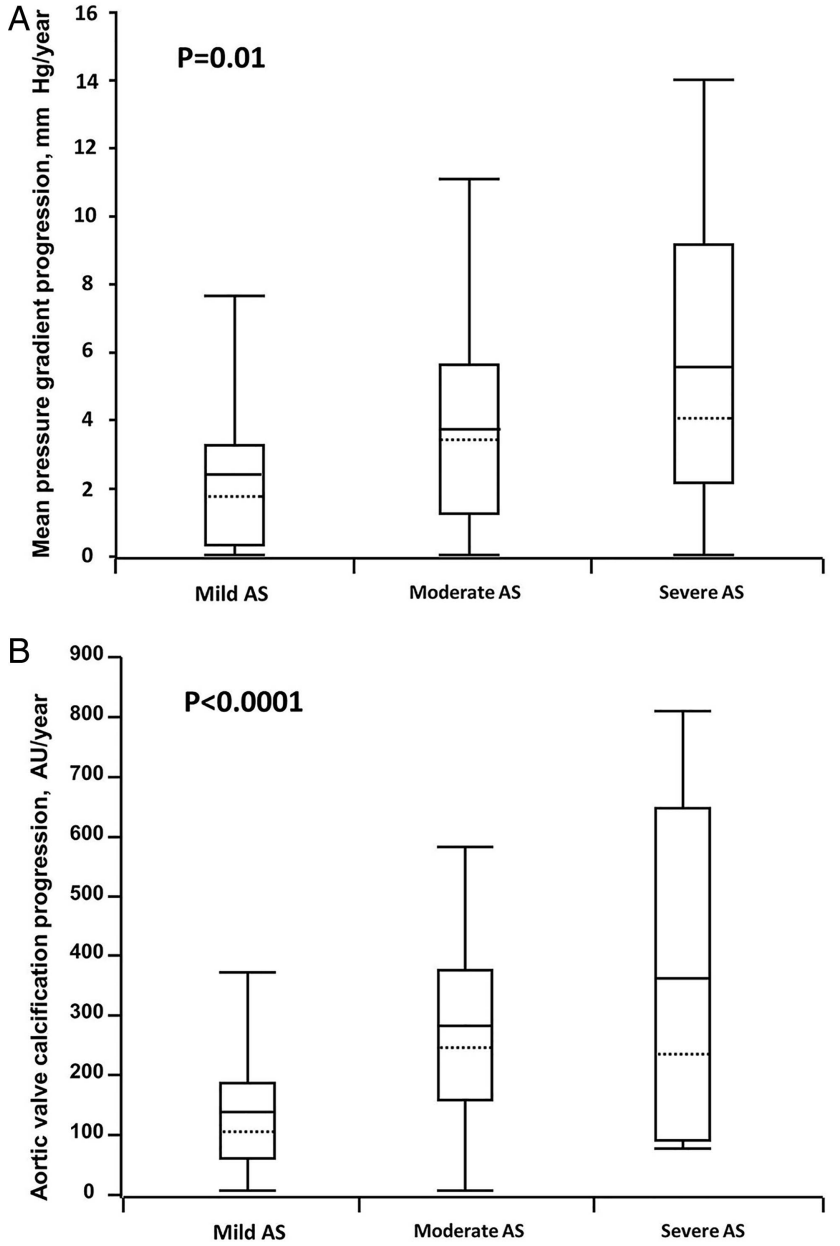

Figure 4 Yearly haemodynamic (A) and anatomic (B) progression according to the degree of severity of aortic valve stenosis. The box defines the IQR with the mean indicated by the full crossbar and the median indicated by the dotted line. The whiskers indicate the 5 th and the 95th percentiles.

increased with AVC terciles (all $\mathrm{p}<0.001$ ). Mean MPG increase was also different between terciles $(1 \pm 1 \mathrm{~mm} \mathrm{Hg}$ in the first tercile, $3 \pm 2 \mathrm{~mm} \mathrm{Hg}$ in the second tercile and $5 \pm 4 \mathrm{~mm} \mathrm{Hg}$ in the third tercile, $\mathrm{p}<0.0001)$. Haemodynamic severity and AVC at baseline were significant predictors of AVC progression in univariate analysis (both $\mathrm{p}<0.0001)$, whereas gender $(\mathrm{p}=0.33)$, age $(p=0.69)$ and valve anatomy $(p=0.20)$ were not. After adjustment for age, gender and valve anatomy, baseline AVC was an independent determinant of AVC progression $(p<0.0001)$.

\section{DISCUSSION}

In this prospective cohort of patients with AS who were followed for up to 5 years, we observed that neither haemodynamic nor anatomic progression were uniform. There was a positive linear correlation between haemodynamic and anatomic progression, but both haemodynamic and anatomic severity at baseline were independent predictors of AS progression, whereas gender and aortic valve anatomy (bicuspid or trileaflet aortic valve) were not.

\section{AVC progression}

If more data accumulate showing that AS is an active process, AS progression remains unpredictable. Similarities with atherosclerosis and bone remodelling have been reported, ${ }^{13-16}$ but statin 
therapy has failed to prevent AS progression in three clinical trials. ${ }^{17-19}$ Annualised AS haemodynamic progression is classically considered as constant and homogeneous $(+7 \mathrm{~mm} \mathrm{Hg} /$ year and $+3 \mathrm{~mm} \mathrm{Hg} /$ year in the Simvastatin and Ezetimibe in Aortic Stenosis (SEAS) trial ${ }^{18}$ ) even if it is highly variable among individuals. However, determinants of AS progression are largely unknown, and the impact of AS severity has rarely been evaluated. We have previously shown in a population-based study that the degree of AVC was an important predictor of AVC progression, but the sample size was relatively small and the impact of baseline haemodynamic severity could not be assessed. ${ }^{20}$ In the present study, we show a strong association between AS haemodynamic or anatomic progression and either baseline AVC score or baseline MPG, PV or AVA and baseline anatomic or haemodynamic severity was an independent predictor of AS progression. Thus, baseline AS severity was a major determinant of AS progression. AS is caused by progressive calcium deposition within the aortic valve leaflets, and calcium load can be accurately measured using MSCT. As in previous studies, ${ }^{5} 6821-23$ a good correlation between AVC score and haemodynamic parameters of AS severity (AVA, PV or mean gradient) was observed. The faster AVC progression with baseline AVC load or AS haemodynamic severity may be regarded parallel to the centripetal hydroxyapatite nodule growth.

Furthermore, if a positive linear correlation between haemodynamic and anatomical annualised changes was observed, the association was only of moderate level. MSCT only identifies calcifications, whereas AS involves calcifications and thickening due to chronic inflammation and fibrosis which are not assessed by this technique. Additionally, we 'only' evaluated the total AVC load within the valve leaflets. One may hypothesise that a localised progression (limited to one cusp or one nodule) may have a different impact on haemodynamic progression than a more diffuse AVC increase.

\section{Clinical implications}

Calcific aortic valve disease was long considered as a degenerative and, therefore, permanent condition. Clinical and histological similarities with atherosclerosis have led to the hypothesis that statins may prevent AS progression. The Scottish Aortic Stenosis and Lipid Lowering Trial, Impact on Regression (SALTIRE), SEAS and Aortic Stenosis Progression Observation: Measuring Effects of Rosuvastatin (ASTRONOMER) trials assessed the effect of statins on progression of AS in asymptomatic patients and failed to demonstrate any effect. ${ }^{17-19}$ It has thus been suggested that any effect of statins may only be observable in the early phase in patients with mild AS or even in patients with aortic valve sclerosis. ${ }^{24}$ Such a strategy seems unrealistic and the cost-effectiveness is questionable as it would require treating one-quarter of the population aged 65 years or older. ${ }^{20}$ The negative results of these trials more reasonably underline the necessity for exploring other pathophysiological pathways, such as calcium-phosphorus metabolism, vitamin D linked to bone remodelling ${ }^{25}$ or impairment of NO signalling. ${ }^{26}$ As we observed, a faster AVC progression with baseline AVC load or haemodynamic severity, if a medical strategy aimed at preventing AVC progression emerges, our study supports the need to treat all subsets of patients with AS, even those with severe AS. Additionally, our results support current guidelines recommending a closer follow-up of patients with AS, as haemodynamic severity increases as these patients are more prone to rapid progression. ${ }^{12}$

\section{Study limitations}

The present study deserves several comments. First, it was a single-centre study. Nevertheless, it was a prospective study with a wide range of AS severity and predefined intervals between visits with both simultaneous (same day) and blinded echocardiographic and CT assessment. Second, we decided to use transaortic MPG for the determination of AS severity as it is more robust and reproducible than AVA. However, our conclusions

Table 1 Baseline characteristics of the overall population overall and according to terciles of progression of aortic valve calcification (AVC)

\begin{tabular}{|c|c|c|c|c|c|}
\hline & \multirow[b]{2}{*}{$\begin{array}{l}\text { Overall } \\
n=149\end{array}$} & \multicolumn{4}{|c|}{ Terciles of AVC progression } \\
\hline & & $\begin{array}{l}\text { First tercile } \\
\text { (<85 AU/year) }\end{array}$ & $\begin{array}{l}\text { Second tercile } \\
\text { (85-205 AU/year) }\end{array}$ & $\begin{array}{l}\text { Third tercile } \\
\text { (>206 AU/year) }\end{array}$ & $\mathrm{p}$ Value \\
\hline Age, years & $74 \pm 9$ & $73 \pm 9$ & $75 \pm 8$ & $75 \pm 10$ & 0.2 \\
\hline Body surface area, $\mathrm{m}^{2}$ & $1.9 \pm 0.2$ & $1.9 \pm 0.2$ & $1.8 \pm 0.2$ & $1.9 \pm 0.2$ & 0.1 \\
\hline Male gender & $112(75)$ & $35(70)$ & $35(71)$ & $42(84)$ & 0.2 \\
\hline Sinus rhythm & $138(93)$ & $48(96)$ & $45(92)$ & $45(90)$ & 0.5 \\
\hline Diabetes & $32(21)$ & $9(18)$ & $14(29)$ & $9(18)$ & 0.34 \\
\hline Hypertension & $102(69)$ & $32(64)$ & $33(67)$ & 37 (74) & 0.55 \\
\hline Smoker & $80(54)$ & $26(52)$ & $27(55)$ & $27(54)$ & 0.95 \\
\hline Trileaflet aortic valve & $125(84)$ & $43(86)$ & $43(88)$ & $39(78)$ & 0.4 \\
\hline Total cholesterol & $4.76 \pm 1.10$ & $4.78 \pm 1.21$ & $4.60 \pm 0.98$ & $4.90 \pm 1.09$ & 0.36 \\
\hline Low-density lipoprotein cholesterol & $2.67 \pm 0.94$ & $2.73 \pm 0.97$ & $2.43 \pm 0.86$ & $2.84 \pm 0.95$ & 0.06 \\
\hline Serum creatinine $(\mu \mathrm{mol} / \mathrm{L})$ & $92 \pm 29$ & $97 \pm 36$ & $87 \pm 21$ & $92 \pm 28$ & 0.67 \\
\hline Calcium (mmol/L) & $2.37 \pm 0.12$ & $2.37 \pm 0.13$ & $2.38 \pm 0.12$ & $2.36 \pm 0.11$ & 0.35 \\
\hline Phosphate (mmol/L) & $1.06 \pm 0.17$ & $1.08 \pm 0.18$ & $1.08 \pm 0.15$ & $1.02 \pm 0.18$ & 0.26 \\
\hline$E F, \%$ & $63 \pm 5$ & $63 \pm 6$ & $63 \pm 6$ & $63 \pm 4$ & 0.5 \\
\hline Baseline aortic valve area, $\mathrm{cm}^{2}$ & $1.41 \pm 0.36$ & $1.57 \pm 0.38$ & $1.38 \pm 0.36$ & $1.29 \pm 0.30$ & 0.0007 \\
\hline Baseline indexed aortic valve area, $\mathrm{cm}^{2} / \mathrm{m}^{2}$ & $0.75 \pm 0.18$ & $0.82 \pm 0.19$ & $0.75 \pm 0.19$ & $0.68 \pm 0.15$ & 0.0007 \\
\hline Baseline MPG, mm Hg & $22 \pm 11$ & $17 \pm 9$ & $20 \pm 6$ & $29 \pm 13$ & $<0.0001$ \\
\hline Baseline peak aortic velocity, $\mathrm{cm} / \mathrm{s}$ & $299 \pm 62$ & $270 \pm 55$ & $290 \pm 41$ & $338 \pm 68$ & $<0.0001$ \\
\hline Baseline AVC score, AU & $1108 \pm 891$ & $775 \pm 761$ & $825 \pm 459$ & $1717 \pm 1020$ & $<0.0001$ \\
\hline Mean MPG increase, mm Hg/year & $3 \pm 3$ & $1 \pm 1$ & $3 \pm 2$ & $5 \pm 4$ & $<0.0001$ \\
\hline Mean AVC increase, AU/year & $188 \pm 176$ & $45 \pm 25$ & $138 \pm 35$ & $379 \pm 175$ & $<0.0001$ \\
\hline
\end{tabular}


remained unchanged when AVAi or PV were used instead of MPG. Finally, the number of patients with severe AS $(n=9)$ and patients with bicuspid aortic valve $(n=24)$ considered in the progression analysis was relatively low. The low number of patients with severe AS is at least partially explained by the fact that only patients with at least 2 years of follow-up were enrolled in the present study. Our conclusions both in the subset of bicuspid patients and patients with severe AS deserve confirmation in larger sample sizes. Additionally, diagnosis of bicuspid aortic valve was based on echocardiography which may be difficult in case of severe calcification. Finally, we decided to enrol only participants with at least 2 years of follow-up to ensure enough time for haemodynamic or anatomic changes to occur.

\section{CONCLUSION}

In a prospective cohort of patients with a wide range of AS severity, we showed that AS progressed faster with increasing haemodynamic or anatomic severity, but there was no difference in progression related to aortic valve anatomy or gender. Our results suggest that a medical strategy aimed at preventing AVC progression may be useful in all subsets of patients with AS including those with severe AS and support the recommended closer follow-up of patients with AS, as the severity of AS increases.

\section{Key messages}

\section{What is already known on this subject?}

Aortic valve stenosis is a progressive disease, but the determinants have not yet been elucidated.

\section{What might this study add?}

The present study clearly shows that baseline severity of aortic stenosis assessed using either echocardiography (haemodynamic severity) or computed tomography (calcium load) influenced the progression rate of the disease.

\section{How might this impact on clinical practice?}

If a medical strategy aimed at preventing aortic valve calcification progression emerges, our study reinforces the need to treat all subsets of patients with aortic valve stenosis, even those with significant AS. Additionally, the present study highlights the need for a closer follow-up as severity of the disease increases.

\section{Acknowledgements We would like to specially thank the team of the Centre $d^{\prime}$ Investigation Clinique for their help and support.}

Contributors Conception and design, or analysis and interpretation of data: VN CC, CE, DM-Z. Drafting the article or revising it critically for important intellectual content: VN, CC, CE, IC, VH, JB, XD, PP, MAC, ME-S and DM-Z. Final approval of the version to be published: VN, DM-Z. Contributors as being responsible for the overall content as guarantors: VN, DM-Z.

Funding VN was supported by a grant from the Federation Française de Cardiologie; The COFRASA (clinicalTrial.gov number NCT 00338676) and GENERAC (clinicalTrial.gov number NCT00647088) studies are supported by grants from the Assistance Publique_-Hôpitaux de Paris (PHRC National 2005 and 2010, and PHRC regional 2007)

\section{Competing interests None.}

Patient consent Obtained

Ethics approval Comité de Protection de Personnes 2006 (COFRASA) and 2008 (GENERAC), Hotel-Dieu, Paris France.

Provenance and peer review Not commissioned; externally peer reviewed.

\section{REFERENCES}

1 Otto CM, Prendergast B. Aortic-valve stenosis-from patients at risk to severe valve obstruction. N Engl J Med 2014;371:744-56.

2 lung $B$, Baron $G$, Butchart EG, et al. A prospective survey of patients with valvular heart disease in Europe: the Euro Heart Survey on Valvular Heart Disease. Eur Heart J 2003:24:1231-43.

3 Nkomo VT, Gardin JM, Skelton TN, et al. Burden of valvular heart diseases: a population-based study. Lancet 2006;368:1005-11.

4 Baumgartner $\mathrm{H}$, Hung J, Bermejo J, et al. Echocardiographic assessment of valve stenosis: EAE/ASE recommendations for clinical practice. Eur J Echocardiogr 2009;10:1-25.

5 Messika-Zeitoun D, Aubry MC, Detaint D, et al. Evaluation and clinical implications of Aortic Valve Calcification by Electron Beam Computed Tomography. Circulation 2004;110:356-62.

6 Aggarwal SR, Clavel MA, Messika-Zeitoun D, et al. Sex differences in aortic valve calcification measured by multidetector computed tomography in aortic stenosis. Circ Cardiovasc Imaging 2013;6:40-7.

7 Cueff C, Serfaty JM, Cimadevilla C, et al. Measurement of aortic valve calcification using multislice computed tomography: correlation with haemodynamic severity of aortic stenosis and clinical implication for patients with low ejection fraction. Heart 2011;97:721-6

8 Clavel MA, Messika-Zeitoun D, Pibarot P, et al. The complex nature of discordant severe calcified aortic valve disease grading: new insights from combined Doppler echocardiographic and computed tomographic study. J Am Coll Cardiol 2013;62:2329-38.

9 Otto CM, Pearlman AS, Gardner CL. Hemodynamic progression of aortic stenosis in adults assessed by Doppler echocardiography. J Am Coll Cardiol 1989;13: $545-50$

10 Cueff $C$, Lepage L, Boutron I, et al. Usefulness of the right parasternal view and non-imaging continuous-wave Doppler transducer for the evaluation of the severity of aortic stenosis in the modern area. Eur J Echocardiogr 2009;10:420-4.

11 Leye M, Brochet E, Lepage L, et al. Size-Adjusted Left Ventricular Outflow Tract Diameter Reference Values: A Safeguard for the Evaluation of the Severity of Aortic Stenosis. J Am Soc Echocardiogr 2009:22:445-51.

12 Vahanian A, Alfieri 0 , Andreotti $F$, et al. Guidelines on the management of valvular heart disease (version 2012): the Joint Task Force on the Management of Valvular Heart Disease of the European Society of Cardiology (ESC) and the European Association for Cardio-Thoracic Surgery (EACTS). Eur Heart J 2012;33:2451-96.

13 Mohler ER III, Gannon F, Reynolds C, et al. Bone formation and inflammation in cardiac valves. Circulation 2001;103:1522-8

14 Otto CM, Kuusisto J, Reichenbach DD, et al. Characterization of the early lesion of 'degenerative' valvular aortic stenosis. Histological and immunohistochemical studies. Circulation 1994;90:844-53.

15 O'Brien KD. Pathogenesis of calcific aortic valve disease: a disease process comes of age (and a good deal more). Arterioscler Thromb Vasc Biol 2006;26:1721-8.

16 Rajamannan NM, Evans FJ, Aikawa E, et al. National Heart, Lung and Blood Institute (NHLBI) Working Group on Calcific Aotic Stenosis. 2010. http:// wwwnhlbinihgov/meetings/workshops/cashtm

17 Cowell SJ, Newby DE, Prescott RJ, et al. A randomized trial of intensive lipid-lowering therapy in calcific aortic stenosis. N Engl J Med 2005:352: 2389-97.

18 Rossebo $A B$, Pedersen TR, Boman $K$, et al. Intensive lipid lowering with simvastatin and ezetimibe in aortic stenosis. N Engl J Med 2008;359:1343-56.

19 Chan KL, Teo K, Dumesnil JG, et al. Effect of Lipid lowering with rosuvastatin on progression of aortic stenosis: results of the aortic stenosis progression observation: measuring effects of rosuvastatin (ASTRONOMER) trial. Circulation 2010;121: 306-14.

20 Messika-Zeitoun D, Bielak LF, Peyser PA, et al. Aortic valve calcification: determinants and progression in the population. Arterioscler Thromb Vasc Biol 2007;27:642-8

21 Cowell SJ, Newby DE, Burton J, et al. Aortic valve calcification on computed tomography predicts the severity of aortic stenosis. Clin Radiol 2003;58:712-16.

22 Koos R, Mahnken AH, Sinha AM, et al. Aortic valve calcification as a marker for aortic stenosis severity: assessment on 16-MDCT. AJR Am J Roentgenol 2004;183:1813-18.

23 Morgan-Hughes GJ, Owens PE, Roobottom CA, et al. Three dimensional volume quantification of aortic valve calcification using multislice computed tomography. Heart 2003:89:1191-4.

24 Antonini-Canterin F, Hirsu M, Popescu BA, et al. Stage-related effect of statin treatment on the progression of aortic valve sclerosis and stenosis. Am J Cardio 2008; 102:738-42.

25 Hekimian $\mathrm{G}$, Boutten A, Flamant $\mathrm{M}$, et al. Progression of aortic valve stenosis is associated with bone remodelling and secondary hyperparathyroidism in elderly patients - the COFRASA study. Eur Heart J 2013:34:1915-22.

26 Sverdlov AL, Ngo DT, Chan WP, et al. Determinants of aortic sclerosis progression: implications regarding impairment of nitric oxide signalling and potential therapeutics. Eur Heart J 2012;33:2419-25. 